\section{Africa's academies}

\section{Robust scientific institutions won't be built in a day.}

ast month in Dakar, Senegal, representatives of scientific academies, science ministers, donors and development specialists -gathered to take stock of a multi-year project to develop stronger scientific academies in Africa, led by the US National Academies and funded by the Bill \& Melinda Gates Foundation.

The African Science Academy Development Initiative (ASADI) has been undertaken on the assumption that both scientists and nations stand to benefit from the existence of robust, well respected and reasonably independent institutions that can speak forcefully and effectively for science. Elsewhere in the world, such bodies serve to sustain excellence within the scientific community itself, to foster informed public discourse on science-related issues and to provide policy-makers with sound advice on these issues, encouraging rational decision-making.

Some solid progress has been made since ASADI got under way in 2004. Initially, the initiative has concentrated on providing intensive support for academies in South Africa, Nigeria and Uganda. These projects are each at different stages of development. South Africa already had an academy structure, albeit one fragmented by the legacy of apartheid. Nigeria has a troubled history and vast, unmet needs. Uganda has a young academy, striving to make its presence felt in a relatively open political environment. ASADI also provides more modest support to academies in Senegal, Ghana, Cameroon and Kenya, and to the African Academy of Sciences in Nairobi.
The goals of the project are more abstract than those of most development efforts in science and medicine. But the establishment of credible institutions (such as scientific academies) is needed to underpin broader economic and social development and the dearth of such institutions is a critical problem in much of Africa.

Organizations such as the Royal Society in London and the National Academies in Washington DC have taken many decades to build up their respective positions. Although occasionally lampooned as self-important associations of elderly white males, they are in fact important components of good governance. Their voices command respect, even in the most disrespectful corners of the media, and their advice is widely sought.

ASADI is providing long-term support to establish staff and premises for its three target academies, which are starting to do useful work. The Academy of Science of South Africa, for example, produced a comprehensive study in August on AIDS and tuberculosis. The Ugandan academy is reporting on the use of DDT to control mosquitoes indoors. The Nigerian academy has held workshops on blood safety and infant mortality. Getting governments to follow through on such work remains a major challenge, however.

The African academies need to establish a level of recognition with their respective publics and governments, and then to make that recognition stick in a climate where influence is often ephemeral. Building up that recognition will require careful, unspectacular legwork over many years. The Gates Foundation will consider continuing funding for the project next year and will do well - if the quality of the emerging academies' work is high enough - to support it over the long haul.

\section{Shared genomes}

\section{Nature's publishers are expanding the licence for reuse of genome papers.}

A lthough Nature and the Nature journals are built on a business model funded by subscribers and other sources of revenue, various initiatives have been implemented to enhance the accessibility of the research papers published in these journals.

They have long been freely available to researchers in the 100 or so poorest countries through the World Health Organization's Hinari initiative and others like it. Machine access is being enhanced by the open text-mining initiative of the Nature Publishing Group (NPG) (http://opentextmining.org). Preprints of original versions of papers can be deposited in arXiv (http://arxiv.org) and Nature Precedings (http://precedings.nature.com) without compromising their acceptability for publication. And final authors' versions of papers can be deposited in PubMed Central and other public servers from six months after publication. Authors retain copyright of their work, whereas NPG retains the licence to publish it.

For many years, a more generous arrangement has been made for papers reporting full genome sequences. (The paper reporting the sequence and analysis of 12 species of Drosophila is the most recent example, see Nature 450, 203; 2007). These papers are freely accessible on NPG's website from the moment of publication. This recognizes a consistent character of 'genome' papers: they represent the completion of a key and fundamental research resource, describing and reflecting on what has been revealed but not usually providing insights into mechanism. Although some papers in other disciplines might also be characterized in this way, the fundamental character of the genome has led NPG to make a systematic exception.

In the continuing drive to make papers as accessible as possible, NPG is now introducing a 'creative commons' licence for the reuse of such genome papers. The licence (see www.nature.com/authors/ editorial_policies/license.html) allows non-commercial publishers, however they might be defined, to reuse the $\mathrm{pdf}$ and html versions of the paper. In particular, users are free to copy, distribute, transmit and adapt the contribution, provided this is for non-commercial purposes, subject to the same or similar licence conditions and due attribution.

In 1996, as human genome sequencing was getting under way, leading players stated: "It was agreed that all human genomic sequence information, generated by centres funded for large-scale human sequencing, should be freely available and in the public domain in order to encourage research and development and to maximise its benefit to society" (see www.ornl.gov/sci/techresources/Human Genome/research/bermuda.shtml). These principles have continued to guide the field, and NPG has consistently made genome papers freely available in keeping with them. This new licence allows us to formalize the arrangement. 